\title{
Utilizing Flipgrid Application on Student Smartphones in a Small-Scale ESL Study
}

\author{
Jacob B Petersen ${ }^{1}$, Simon DC Townsend ${ }^{1} \&$ Natsumi Onaka ${ }^{1}$ \\ ${ }^{1}$ Global Education Center, Iwate University, Morioka, Iwate, Japan \\ Correspondence: Jacob B Petersen, Global Education Center, Iwate University, Morioka, Iwate, Japan.
}

Received: March 31, 2020

Accepted: April 24, 2020

Online Published: April 27, 2020

doi: $10.5539 /$ elt.v13n5p164

URL: https://doi.org/10.5539/elt.v13n5p164

\begin{abstract}
The purpose of this study is to evaluate the efficacy of utilizing 'Flipgrid,' a PC and mobile device video recording and social media application, as a means of practice in an English communication class. The present small-scale study was conducted at a Japanese national university in a first-year ESL classroom. The practical implications of this study inform on innovative ways to improve communicative English engagement in higher learning education. In this case, student presentation videos and online video discussion tasks were recorded using the Flipgrid application on student smartphones. The data collection methods consisted of teacher observations, video data and student responses recorded via a questionnaire. For the researchers, taking these first steps impacts broader language and technology research in the future.
\end{abstract}

Keywords: ESL, flipgrid, student engagement, video application

\section{Introduction}

The Japanese Ministry of Education faces increasing challenges with regard to English learning and teaching, especially with one of the main reforms pointing towards speaking proficiency (Steele \& Zhang, 2016). This has led to a new trend in language learning and teaching methodology in Japan to redirect English education towards a more communicative development and learning process (Wilkinson, 2015). In our case, this small-scale study is intended to be the starting point part of a broader program to develop more effective English communication courses utilizing technology (Given, 2016). One of the main problems that exists for an educator is knowing what technology best supports specific learning aims and objectives. In addition, how to set up technology and access a program's functionality, then later collect and evaluate the students' work, may be challenging. In technology-based procedures, a specific framework is required to integrate technology as a tool to aid in learning (Townsend \& Cronin, 2017). In this case, language activities were prepared based on science topics using National Geographic readers; therefore, all that was needed was a tool to record 'speaking' videos and to share them on a social networking platform. Flipgrid was selected due to its recording and sharing functionality, as well as its cross-device capabilities. Additionally, in a broader learning context the use of a rubric to allow the teacher to provide effective feedback was trialed, and our findings show that further research is needed to understand the full potential of a video comment function for giving and receiving effective feedback.

The methodology applies a qualitative approach with the aim to 1) determine if first-year students are suited to this type of evaluative based study, 2) test the usability and performance of the technology, 3) learn the implications of the project design and 4) provide initial evidence to support future project development. One of the main factors for the evaluation of the technology was to determine how well students were able to use smartphones, as opposed to using a PC, in a traditional CALL environment. Furthermore, a qualitative student questionnaire that recorded students' perceptions and attitudes was conducted at the end of the study. The implications of these results will be discussed to provide teachers with insights into possible difficulties faced, as well as to highlight the potential for further development in integrating speaking related activities using smartphone applications in an ESL classroom.

\section{Language Education}

Since the early 2000's Japan has recognized that the English communication skills of university graduates were relatively low compared to the rest of the world. This has prompted different reformations and the creation of other language learning programs to improve the communicative ability of students (Butler \& Iino, 2005). For example, in 2001, CEFR (Common European Framework of References for Languages) added to the older model of CLT 
(Communicative Language Teaching) that had been used since the 1980s (Steele \& Zhang, 2016). Even after educational reforms had been instigated, there was a public perception that English education needed further changes because the desired improvements and overall communicative results were still lacking (Wilkinson, 2015). As a result, there has been an urgency for increased efforts focused on communication, rather than the traditionally emphasized reading and writing skills (Okada et al., 2018). Since educators are required to develop such English teaching strategies, it has become imperative for teachers to find or create new ways to engage students in English communication practices.

\subsection{ICT Background Information}

The beginning of the Information and Communications Technology (ICT) program at our university in Japan was due to the result of a successful proposal submitted to the Ministry of Education, Culture, Sports, Science and Technology (MEXT) in 2010. For the Global Education Center (GEC) at the same university, the purpose of this newly founded program was to expand and support the development of language teaching and learning. A decision was made by GEC to design and implement learning/teaching programs using a Learning Management System (LMS) called Moodle. Since 2010, the design of the online learning and teaching framework has expanded to include four content categories: 1) general education, 2) educational contents related to specialized areas, 3) self-study and 4) preparatory content for new students entering the university. In addition, the GEC department conducts specialized courses and programs, such as the Intensive English Program (IEP), an advanced speaking preparation course and Super English, designed for student study abroad programs. One problem the university has faced in recent years is that due to a lack of funding for CALL classrooms and outdated PC's, alternative ways in technology-assisted learning needed to be explored. For example, the department has considered providing tablets to students or requesting that students use their own laptop computers and other such devices, including smartphones, in class. As a result, a pilot study was necessary to determine the efficacy of using such alternative devices and online applications for language learning. For the current small ICT team, an idea based on the reformation of communicative language teaching and learning has prompted a new and innovative pilot study. However, before the pilot study can begin, a pilot phase to test and evaluate Flipgrid was deemed necessary. Based on this premise, the research was designed to test the integration of Flipgrid with Moodle, evaluate the setup of video activities in an online course and to enable students to complete speaking activities using their smartphones in small social media groups.

\subsection{Online Communicative Teaching}

Mohamad Ali and Jabar (2016) implemented assignments based on video projects to Malaysian ESL grade 5 primary students and reported that video projects versus non-video projects were more enjoyable for the students. In addition to this, test scores showed that the students' overall vocabulary skills increased. In conjunction, another study showed that students tend to have a positive attitude towards online learning, especially if the activity promotes student friendliness towards others and is socially engaging (Dogoriti, 2015). Current internet developed systems and applications that are more dynamic and engaging, also referred to as Web 2.0 , have introduced new pedagogies for teaching and learning, as well as have encouraged a student-centered collaborative learning environment (Mohd Hafiz Zakaria, Watson, \& Edwards, 2010). In Japan, communication and cultural competence are deemed important in English education (Okada, Swaumi, \& Ito, 2018) and Social Networking Sites commonly associated with Web 2.0 have been proven to enhance communicative and cultural competence (Borau, Ullrich, Feng, \& Shen, 2009), which aligns with Japan's English education reformation aims. To conclude, it was recognized that by having second language learners video record themselves, they might be able to improve their communication skills as they are forced to reflect and continually practice the target language (Okada, Sawaumi, \& Ito, 2014, Shrosbree, 2008).

\subsubsection{Integrated technology}

\subsubsection{Flipgrid}

Flipgrid is an Internet application that can be used as a standalone app on smartphones and other devices or as an integrated application. In this case, Flipgrid was integrated into an activity component of the Moodle LMS. Since research suggests that Web 2.0 applications appear to be beneficial for engaging and encouraging students within an online learning community, it was decided to look into a video recording application that would be useful for English communication classes. When researching Flipgrid, there were many positive studies discussing the use of this web-enhanced tool. For example, Flipgrid was recognized as a low-stakes platform that helped students hone their public speaking skills (McClure \& McAndrews, 2016). As well, using Flipgrid helped to bring more UDL (Universal Design for Learning) into the classroom by allowing students to also engage in verbal discussions, not only text-based ones (Flanagan, 2019). The use of Web 2.0 technologies, such as Flipgrid, in the classroom, 
provides a way for students to become more comfortable using videos in an ever-changing technological world. This was supported when undergraduate business university students in South Korea reported that they became more comfortable speaking in English via videos after using Flipgrid over the period of a semester course (McLain, 2018).

\subsubsection{Moodle}

Moodle is a Learning Management System (LMS) used at the university for this study. As described by Petersen (2015):

"These systems [LMSs] allow instructors to facilitate an entire class online. LMSs allow instructors to upload materials and documents, link to other websites and videos, and create and grade assignments. Instructors can also manage interactive activities such as blogs, journals, wikis, discussion boards, and video conferencing tools (p. 4)"'.

In the United States, most universities use LMSs to facilitate their online courses (Allen \& Seaman, 2013). For the purpose of this study, Moodle was used as a method to enhance the traditional face-to-face class with digital assignments and the embedding of Flipgrid so that the students were able to have access to all course content, for example, rubrics, outlines and documents, in one location.

\subsubsection{Smartphones}

Records show that $70-90 \%$ of people in Japan have a smartphone with $95 \%$ of the internet broadband speeds being LTE or higher (International Telecommunications Union, 2019). Those numbers would imply that most students in a university would have access to a smartphone and high-speed internet. Even with the large number of students with smartphones, some educators are still concerned as to whether or not mobile technology is useful in an educational setting (Motiwalla, 2007). Because educators may not understand how best to teach with the inclusion of mobile devices, it is important to create new educational approaches where the students are at the center of teaching and learning and therefore playing an active role in their educational process (Ozdamli \& Cavus, 2011). It was found that general access to mobile technology by itself was not enough to enhance student performance in the classroom because students, when self-directed, tend to only use basic web and email functions for schoolwork (Tossell et al, 2015). The hope of this study was to remove the concerns of using smartphones in an ESL classroom, and that by giving students specific smartphone applications to use, the students would have more interactions and positive results.

\subsection{Program Goals and Objectives}

As mentioned earlier, MEXT wants to improve the English communication of students though interactive, communicative and cultural tasks (Wilkinson, 2015). Due to class sizes, it can difficult to implement speaking activates in class; therefore, it was decided that Flipgrid would aid in such tasks by having the students interact through Web 2.0 technologies in a non-threatening way. By using CEFR levels as a guide, this study aimed to align appropriately leveled National Geographic readers. The teachers' aim was to implement video-based activities in the classroom to help prepare students for engaging online tasks through Flipgrid. It was expected that speaking and discussion-based activities would also facilitate communication and encourage students to use English in a more commonly utilized real world way, e.g., something akin to video conferencing.

\section{Methodology}

The methodology is set up to evaluate a small-scale project that required students to use their own smartphones to conduct speaking activities based on science content. Given (2016) defines, "A pilot study is a small-scale phase of a larger project, which is designed to test the approaches that will be used in the final study" (p. 112). Given continues to provide the following areas for conducting initial research and states that, "Pilot studies allow researchers to:

- $\quad$ Practice and refine research instruments.

- Ensure that a participant type is fit for the study.

- Explore a new research site.

- Test equipment.

- Assess how long data collection will take to complete.

- Feel more at ease with the project design.

- $\quad$ Provide initial evidence/publications to support future project development work. 
- Test relationships with new co-investigators or new community/industry partners.” (2016, pp. 112-113)

This small-scale study's aim is to evaluate a technological application to assist language learners engaging with second language production on such an application the first time, and if successful, Flipgrid will be implemented as part of a broader program involving creating language courses online with speaking components. We begin this methodology by selecting four areas of Given's outline, which were considered applicable for evaluation in this initial pilot study:

Area 1: Ensure that a participant type is fit for the study.

Area 2: Test equipment.

Area 3: Feel more at ease with the project design.

Area 4: Provide initial evidence to support future project development work.

The research methods will first provide information on the participants of this study, and next the lesson framework will be outlined. The data collection methods and analysis procedures will be given followed by the research question and the roles and goals of the study.

\subsection{Participants}

An intermediate to high-level communication ability freshmen university class of 37 students was selected for this study. The class consisted of students enrolled in agriculture and engineering courses. These participants are recognized as today's "Gen Z" (Dimock, 2019) and have grown up with easy access to digital resources. Therefore, students were all expected to own and use smartphones in class and outside of class for speaking tasks and exercises. In addition, this class was conducted in semester one and two with the same teacher. For this reason, if this study proved to be feasible, the experience gained by these students would benefit a second larger-scale study.

\subsection{Lesson Framework}

A short description of the lesson activities and use of Flipgrid conducted from week five through week eleven is separated into a trial stage (Table 1), exercise stage one (Table 2) and exercise stage two (Table 3).

Before the study was implemented, it was decided that it was best to make sure that the students were able to engage effectively with the technology and the teachers were able to manage the lesson activities. To ensure that the pilot was ready, the researchers created a trial run to see if the participants were able to use Moodle and Flipgrid (see Table 1), made notes on the student comfort level with the process, tested the functionality of smartphones in the classroom and learned how difficult it would be for teachers 1 and 2 to control and administer the software in later stages.

Table 1. Flipgrid Trial Stage

\begin{tabular}{cr}
\hline Week & Activity outline and objective \\
\hline W5 & Preliminary trial was set up to conduct testing (week 6) of 1) application download, 2) video \\
& upload into Flipgrid, 3) video sharing in groups, 4) and finally, video responses. \\
W6 & Flipgrid trial conducted in class and the trial videos made in small groups were recorded
\end{tabular}

uploaded and later shared.

The main purpose was to evaluate the students' capability when using Flipgrid on their smartphones to handle English video speaking tasks based on National Geographic (NatGeo) science reader topics. Two reader exercises were used for lesson activities for which the details are provided in Table (2) and Table (3).

Table 2. Language Reader Exercise I

\begin{tabular}{cc}
\hline Week & Activity outline and objective \\
\hline W7 & $\begin{array}{c}\text { Science topic readers by 'National Geographic' (NatGeo), level 2, were introduced to } \\
\text { students to prepare them for their first small group science video-speaking activity. }\end{array}$ \\
W8 & $\begin{array}{c}\text { Students partook in a class activity to prepare for their first video-speaking activity using } \\
\text { topics based on the NatGeo readers. Students created topic videos in Flipgrid outside of class. } \\
\text { This week included a short 1-minute video presentation of the topic and video responses } \\
\text { included a Q\&A. }\end{array}$ \\
\hline
\end{tabular}


Table 3. Language Reader Exercise II

\begin{tabular}{cr}
\hline Week & Activity outline and objective \\
\hline W9 & $\begin{array}{r}\text { Students did additional reader activities to prepare for a discussion using the reader section } \\
\text { 'Explore the Issue', and students produced response videos to their group members to make } \\
\text { comments and share their opinions about the topic, including a Q\&A component. } \\
\text { Students read and participated in-class activities using the reader section 'Case Study' to } \\
\text { prepare a 3-minute presentation to explain the problem presented in the case study. } \\
\text { W11 }\end{array}$ \\
$\begin{array}{r}\text { Students took part in-class activities using groups to prepare for the discussion section of the } \\
\text { case study that required students to present and discuss solutions to the problem. }\end{array}$ \\
\hline
\end{tabular}

\subsection{Data Collection Methods and Analysis Procedures}

\subsubsection{Participant Type (Area 1)}

In class, students were expected to complete exercises (see Section 3.2) to achieve language goals and speaking objectives. Outside the class, students were expected to use Flipgrid for video recording in the form of short presentation videos, question and reply videos and comment videos. Activity completion and video performance were observed by both teachers 1 and 2 to confirm how well language goals and speaking objectives were achieved (Given, 2016, p. 112). Creswell suggests that, "a hallmark of good qualitative research is the use of multiple sources of data in a project" (2016, p. 112). In our case, this includes observations of student participation in class (teacher 1) and video materials (teacher 2) in the form of student speaking videos. Teacher 2 joined each group online, watched the videos, observed the students' performances and provided language and speaking feedback in the rubric outside class. These results will be given in section 4.1.

Therefore, the students' video data and both of the teachers' overall observations will reflect on the efficacy of utilizing the video app as a part of the learning framework in the future. The study aims to determine whether or not first-year students are capable of using the video application 'Flipgrid' on their smartphones to create presentations and discuss science topics in small groups.

\subsubsection{Test equipment (Area 2)}

A report detailing the testing of the equipment was conducted and then divided into two parts by teacher 2 (see Section 4.2). The first part was a report on the process of integrating the Flipgrid software plug-in with Moodle (LMS). The second part was a technology performance report, which is a term used to describe the suitability of the application to be used on smartphones. For example, it is a known factor that Android and Apple phones have quirky differences in running media applications. It is duly noted that unknown factors in this study could exist due to device issues and user limitations, but we hoped to mitigate it by practicing with the students, "By testing equipment in advance, during a pilot phase, a researcher will become more comfortable with the technology, reducing the chance of human error" (Given, 2016, p. 113), and if there were any problems, we would have to move to a backup. However, due to the time constraints in this study, only a small 2-week 'Flipgrid Trial Stage' was implemented (see Table 1). If this test failed and students were not able to download the app onto their smartphone and use the video app instantaneously, then the backup plan would have been to suspend the study and later provide a small training course on how to use the video app.

\subsubsection{Project design comfort (Area 3: Feel more at ease with the project design)}

Area 1 and Area 2 of this pilot phase tested the video application Flipgrid for carrying out speaking activities based on science topics for first-year students. It is hoped that as part of the next stage of this study, Flipgrid can be implemented in speaking and communication classes taught by both Japanese and native English language teachers (category 1) as mentioned in 2.1. Also, as the GEC department conducts specialized courses and programs (category 2), thus the implementation of an online and video application such as Flipgrid would provide an effective way for students to participate in various speaking exercises. With that in mind, the purpose of evaluation area (3) is to determine how well the lesson framework, namely the activity procedures, language aims and objectives, can potentially transfer into the design of online learning and teaching hosted by the ICT team. Because the study is looking at feasibility, the learning framework was not evaluated. As Creswell clearly points out, "it is difficult to analyze everything that you observe" (2016, p. 118), and in this case, observations are focused on and are "designed to test the approaches that will be used in the final study" (Given, 2016, p. 112). In addition to observing student engagement, it is expected that the data in the student questionnaire will gather a more complete picture of the students' learning experiences (see Section 4.3). 


\subsubsection{Provide initial evidence to support future project development work (Area 4)}

As a pilot-phase study, we needed to gather initial data as a "proof of concept" so that we could validate continuation (Given, 2016). For example, if the option of using smartphone videos was too difficult, then another technology solution may need to be considered. Or if the study concluded that first-year participants were unable to complete language exercises using their smartphone devices, then an alternative teaching methodology and other materials would be necessary. "Typically, qualitative observers start with broad observations and then narrow their view to information that will answer their research question" (Creswell, 2016, p. 118). Therefore, whatever the observations revealed, the students' thoughts about using their smartphones and the recording and sharing of videos was deemed to have considerable influence on continuation and future development of this study. Due to this, a five-point Likert scale questionnaire (administered in Japanese) was used for its reliability by asking students how much they agree or disagree (Allen \& Seaman, 2007) according to: 1) the usability of Flipgrid; 2) conducting Flipgrid activities; 3) using Flipgrid for discussion and assessment; and 4) the overall functionality of Flipgrid. The student questionnaire will inform on the lesson framework and overall design of the technology coupled with language and speaking exercises. The student questionnaire was conducted at the end of the course and the student responses are presented in Section 4.3.

\subsection{Research Question}

Although a qualitative paradigm was designed, it is recognized that "quantitative research can complement qualitative projects" (Given, 2016, p. 103) to provide a rich picture of the experience. Primarily, the research design and processes were to integrate Flipgrid with Moodle and setup speaking activities via students' smartphones. If it is deemed that the pilot was successful, the next process is for the GEC to implement a 'category 2' component (see Section 2.1) for undergraduate and postgraduate listening and speaking classes and general communication classes. The qualitative data will be evaluated alongside the quantitative data results from the student questionnaire to answer the research question.

We specifically asked;

What was the efficacy of integrating and utilizing a video application for recording, uploading and sharing student English videos via student smartphones?

\subsubsection{Roles and goals}

In this study, the roles of the teachers are as follows. Teacher 1 prepared the lesson framework (see Section 3.2), conducted the lesson, answered student questions and addressed any concerns and provided feedback on lesson progress and achievement in class. The main technological role was given to teacher 2 . This involved managing Flipgrid, creation of Flipgrid activities, providing the online video-rubric feedback and giving technical support outside the classroom. Teacher 3 carried out the administrative duties to support the study, such as translating the survey from English to Japanese, and did not partake in any observations. During the first two weeks, both teacher 1 and teacher 2 were present for the initial trial in the classroom. Under the definitions of observer roles (Creswell, 2016, p. 121), Teacher 1 was a "complete participant: the researcher is fully engaged with the people he or she is observing". Due to the fact that teacher 2 is not teaching in the classroom, this role is defined as a 'nonparticipant/observer', however, teacher 2 did give online video feedback in the rubric and additionally provided technical support outside the classroom. Teacher 2 also reported on the installation of the video app prior to the trial. Teacher 3 is defined as a 'complete observer' and did not have any contact with the students.

\section{Results}

The results below outline the four areas concerned with the evaluation of this study and provide an initial trial with the participants (4.1), the testing of the equipment (4.2) and the student questionnaire to evaluate Area 3 and Area 4 (4.3) to later discuss the feasibility of the study (5) as well as the implications for further research (5.1).

\subsection{Ensure that Participants Fit the Study Type (Area 1)}

In the initial trial (see Table 1), students were able to follow specific instructions to download the Flipgrid app onto their smartphones. In exercise 1 (see Table 2), students learned how to identify key vocabulary and main points based on their science topic in class, which was checked by teacher 1 (in class). Next, students were shown how to prepare a short video (1 minute) for homework. For homework, students recorded and uploaded their videos and shared them with their groups. In addition, groups shared short Q\&A videos to further discuss the topic. Students also made comment videos to give their opinions and/or to agree or disagree with each other. Evidence observed by teacher 2 confirms that in exercise 2 (see Table 3), all students recorded a three-minute video and discussed solutions to problems through a video discussion task. 
In summary, all groups were able to learn how to upload and share videos using Flipgrid in small speaking groups. In addition, the feedback given by the teacher was used in a class exercise to improve video presentations. The students were able to read feedback based on their speaking strengths and weaknesses, then demonstrated to the class teacher that changes were attempted to improve their videos, which was also confirmed by teacher 2 in the final video assignment.

\subsection{Test Equipment (Area 2)}

Preparing Flipgrid for use in this project was a straightforward process. To create a free administrator account, one needs to use an existing Microsoft or Google account. Once an account is created, a teacher is able to see their list of grids, a Flipgrid label, for a learning space in which an instructor can create many video tasks. When an account is created there is only one grid, but an instructor is able to make as many as they like. For this research, a grid for each of the ten participating groups was created. A useful function of Flipgrid is that once an instructor makes a "topic" (assignment), they can easily duplicate it across each grid. When using Flipgrid for a class, there are two major items that need to be taken care of: 1) how students are enrolled into the grids; and 2) topic creation.

\subsubsection{Grid Enrollment}

When an instructor creates a new grid, they are required to designate how the students will access the grid. As of the writing of this paper, there are three options. Option one is to use Microsoft or Google student emails. The second option is to make a public grid which is open to all Flipgrid users across the world. The last option is to use created student IDs. For this research, it was decided to use option 3, the student ID route, because the school does not use Microsoft or Google accounts campus-wide and public grids were deemed to have privacy issues. When using the student ID method, the instructor is required to manually create a username for each student. There is a way to speed up this process by using a .csv file, but it is worth noting that this method actually seems to be the most tedious. Once the students were added to the Flipgrid course it was a matter of designating which student belonged to which grid.

\subsubsection{Topics}

When creating a new topic, an instructor is required to provide a title and description. It was found useful to put the assignment instructions in the description box. One constraint was that the description box was limited to 500 characters and there was no method to attach a document to the description, however, there were options to link to other applications such as Google Docs. Additionally, instructors are allowed to record videos to serve as an example or description.

\section{Flipgrid video data download}

Accessing student usage and engagement information was simple due to Flipgrid's export data tool. If an instructor wanted a snapshot of a whole grid, they could export the data from that level to get the overall numbers showing student usage for each group. When exporting data, Flipgrid provides a .csv file to download.

\section{Flipgrid and rubrics}

At any time during video creation the students had access to the rubric in Flipgrid. This was imperative in order for Flipgrid to meet our rubric needs. Flipgrid allows for two types of rubrics, either the default rubric or a simple 'create a new rubric' function. In order to follow academic standards, the rubric creation method was chosen. During rubric creation, the instructor is allowed to make as many criteria as desired with set point values.

\subsection{Feel at Ease (Area 3) and Evidence to Support Future Work (Area 4)}

The student responses from the questionnaire are divided into tables in order to evaluate the four areas of Flipgrid outlined in the methodology. The score presents five levels for students to rank the lowest score (\#1) to the highest score (\#5). The questions are given followed by the ranking results as scored by the students. These results intend to assist the evaluation of the study in both area (3) 'Feel more at ease with the project design' and area (4) 'Provide initial evidence to support future project development work.' These findings will be later discussed (see Section 5) to give an overall estimation on the benefits and shortcomings throughout the study. 
Table 4. Usability of Flipgrid

\begin{tabular}{|c|c|c|c|c|c|}
\hline \multirow[t]{2}{*}{ Question Number 1 to 6} & \multicolumn{5}{|c|}{ Score pane (\#) } \\
\hline & $\# 1$ & $\# 2$ & $\# 3$ & \#4 & $\# 5$ \\
\hline $\begin{array}{l}\text { 1. Logging into Moodle course using the web browser on smartphones was } \\
\text { uncomplicated }\end{array}$ & 2 & 2 & 10 & 14 & 8 \\
\hline 2. Downloading the Flipgrid application onto a smartphone was straight forward & 2 & 1 & 2 & 12 & 19 \\
\hline 3. Using the Flipgrid key to access the video activity was easy & 1 & 3 & 7 & 12 & 13 \\
\hline $\begin{array}{l}\text { 4. Recording and uploading videos using Flipgrid application on smartphone } \\
\text { was simple }\end{array}$ & 1 & 3 & 6 & 6 & 20 \\
\hline 5. The Flipgrid video screen display was useful & 1 & 4 & 5 & 10 & 16 \\
\hline 6. Flipgrid emoticons and other artwork were useful & 1 & 1 & 9 & 8 & 17 \\
\hline
\end{tabular}

Table 5. Conducting Flipgrid activities to conduct presentation videos

\begin{tabular}{lllllll}
\hline Question Number 7 to 10 & \multicolumn{3}{c}{ Score pane (\#) } \\
\cline { 2 - 6 } & $\# 1$ & $\# 2$ & $\# 3$ & $\# 4$ & $\# 5$ \\
\hline $\begin{array}{c}\text { 7. Lesson activities were necessary for language preparation to later conduct a } \\
\text { video presentation }\end{array}$ & 1 & 2 & 0 & 12 & 21 \\
$\begin{array}{c}\text { 8. Uploading a presentation video is a suitable method for submitting a video for } \\
\text { class work }\end{array}$ & 1 & 2 & 6 & 9 & 18 \\
$\begin{array}{c}\text { 9. Lesson videos made available to everyone to watch in class or in small groups } \\
\text { is an acceptable part of language learning }\end{array}$ & 1 & 1 & 4 & 6 & 24 \\
$\begin{array}{c}\text { 10. Flipgrid videos in English using science-based content supported the } \\
\text { learning process }\end{array}$ & 1 & 2 & 1 & 14 & 18
\end{tabular}

Table 6. Using Flipgrid for discussion and rubric assessment

\begin{tabular}{|c|c|c|c|c|c|}
\hline \multirow[t]{2}{*}{ Question 11 to 18} & \multicolumn{5}{|c|}{ Score pane (\#) } \\
\hline & $\# 1$ & \#2 & $\# 3$ & \#4 & \#5 \\
\hline $\begin{array}{l}\text { 11. Using video messaging was a simple and effective way to interact with other } \\
\text { students }\end{array}$ & 1 & 3 & 5 & 10 & 17 \\
\hline $\begin{array}{l}\text { 12. Video replies are a suitable way to discuss a topic by asking and answering } \\
\text { questions and making comments }\end{array}$ & 1 & 4 & 7 & 10 & 14 \\
\hline 13. Using a rubric is a suitable method to receive information about schoolwork & 1 & 0 & 6 & 13 & 16 \\
\hline 14. The rubric helped me to improve the poster & 2 & 0 & 4 & 14 & 16 \\
\hline 15. The rubric helped me to improve my speaking & 1 & 0 & 4 & 9 & 22 \\
\hline 16. The feedback comments by the teacher were useful & 2 & 2 & 1 & 7 & 24 \\
\hline $\begin{array}{l}\text { 17. The Flipgrid display of the video, rubric score and teachers' comments visible on } \\
\text { the device display was user friendly }\end{array}$ & 1 & 1 & 4 & 14 & 16 \\
\hline 18. It was useful to receive video feedback from my teammates in class & 1 & 3 & 5 & 12 & 15 \\
\hline
\end{tabular}


Table 7. Overall functionality of Flipgrid

\begin{tabular}{lcccccc}
\hline Question 19 to 20 & \multicolumn{3}{l}{ Score pane (\#) } \\
\cline { 2 - 5 } & & $\# 1$ & $\# 2$ & $\# 3$ & $\# 4$ & $\# 5$ \\
\hline 19. I could use either my PC or smartphone for all language activities & 1 & 3 & 2 & 7 & 23 \\
20. I would be interested in using Flipgrid again in class & 3 & 3 & 9 & 8 & 13 \\
\hline
\end{tabular}

\section{Discussion of Results}

\subsection{Ensure that Participants Fit the Study Type (Area 1)}

To 'ensure that the first-year participants were fit for the study' was primarily the single and most important accomplishment we could have achieved. A significant result is that students reached the final language and speaking expectations set to test the technology. Students demonstrated that they were able to learn and use the science content and complete speaking objectives by making videos. Not only is this result of importance for the students as language learners, but the fact that first-year students were able to complete video tasks outside of class without supervision is also significant for continuing the program. We can conclude from this that it would also be possible to expand the number of first-year students to include other departments, such as humanities and education, to broaden the next study.

\subsection{Test Equipment (Area 2)}

The integration of Flipgrid and Moodle, and the procedure to setup Flipgrid for the students' use, was the first technology test. One of the main hurdles for educators is knowing how to implement and use technology effectively. We recognize that implementing technology for the first time can result in inefficient and deficient outcomes. Often a pilot study performs poorly when testing new equipment due to time restrictions and unexpected costs. Teacher 2 was responsible for setting up Flipgrid and Moodle and managing how Flipgrid was set up and used in the class. Teacher 2 declares that a person with minimal technology experience, such as creating a Facebook page, is all that is required to organize the speaking tasks and setup the users inside of Flipgrid. However, prospective teachers will need to spend time beforehand to become familiar with both the teacher view in Flipgrid, as well as the student view on their devices to know how to troubleshoot any problems.

The second test was evaluating the usability of the video application on student smartphones. Some students in the trial were not able to download the application or upload their videos using their phone's cellular connection resulting in delays due to internet speed and download limits. Even though Flipgrid integrates well with smartphones, some students continued to experience internet connection issues due to their phone's signal strength. Usage of the university's Wi-Fi resolved these issues, indicating that a reliable internet connection is necessary. Even though Flipgrid is simple to navigate from one display to the next, it is understood that as students interacted with Flipgrid more, fewer issues were experienced. In the future, investigating the feasibility for using the campus Wi-Fi to connect all student mobile devices/smartphones to the internet needs to be resolved. In addition, setting up a procedure to support students' learning how to use the video application should be considered for the main study.

The notion of getting "proof of concept" has had considerable bearing towards whether or not this study would continue in the future and is later discussed (Area 4). Due to the fact, students were indeed able to use their smartphones, this finding has provided one solution for budget cutbacks. Additionally, as the student responses in the questionnaire show, the students believed that utilizing smartphones was seen as a positive learning experience.

\section{Usability of Flipgrid}

Questionnaire results for Question (1) showed that students were able to log into and navigate the course using a touch screen device. However, it is recognized that not using a mobile Moodle theme limited viewing and navigation control. To improve Moodle functionality, using the Moodle App and the Moodle standardized theme would enhance the users' control and overall functionality. Question (2) shows that complications existed for some students in locating the application to download in the Google Play or Apple AppStore. Also, some were not able to download the application using their cellular connection, but this issue was resolved by using the university's Wi-Fi. In some instances regarding Question (3), new website access codes for students were generated between 
Flipgrid assignments, requiring prompt instruction by the teacher to ensure all students were able to login to the Flipgrid activity. Question (4) indicates that most students became accustomed to the video upload function. Students continued to experience internet connection issues due to their cellular connection. As mentioned before, these issues were overcome by using the campus Wi-Fi. Question (5) results showed us that the screen display in Flipgrid is simple and navigation from one display to the next is easily recognizable. Question (6) determined that Flipgrid's emoticons may not be suitable for formal speaking situations. However, similar to other SMS applications, this application supports emoticons and editing functions.

Conducting Flipgrid activities to conduct presentation videos

Question (7) shows that language instruction and exercises to prepare students for taking videos were deemed as being highly important. This indicates that preparation work in and outside of class has to be well managed. Question (8) concludes there is next to no concern about using an online application for the uploading and submission of schoolwork in a video format. This result points to the full potential of speaking submissions in other areas of unit work and study. Question (9) shows that even though the researchers assumed that many of the Japanese students would be shy about their peers watching their videos, an unexpected result was the overwhelming student approval of videos being watched by other classmates, both as a whole class or in small group exercises. This shows that students were able to use video work comfortably enough for English based exercises. Question (10) further confirms that using content-based topics in speaking exercises using videos is an appropriate method for practicing various speaking roles.

Use Flipgrid for discussion and assessment

Question (11) indicates that interaction between students was a benefit of using Flipgrid. Video conversations that took place indicated that videos prompted students to speak, make comments and make and reply to questions. Question (12) suggests that student-recorded videos are a suitable means for students to ask topic-appropriate questions and respond to them. Question (13) overwhelmingly showed that the students found the rubric portion of the assignment useful for understanding the assignment. This reinforces the idea that rubric grading is a helpful tool for providing feedback on performance for students and alerting the teachers to student strengths and weaknesses. Question (14) confirmed that the students were able to improve their presentation materials with the aid of feedback. Question (15) showed that most of the students found the rubric feedback helpful for their speaking improvement as well. Question (16) indicates students found the instructor feedback useful to improve upon their current videos in preparation for the next ones. Question (17) suggests that students were able to access feedback with no major issues. Question (18) showed that the students found that peer-reviewed feedback was additionally beneficial for helping students working together in small groups.

Overall function of Flipgrid

Question (19) included the term "PC" in case students needed or chose to use a computer to do their work. This proved to not be the case because all of the students were able to do their tasks on their smartphones. The responses express that students were positive towards using Flipgrid as a video application for conducting speaking activities, although it is recognized that teacher instructions for lesson exercises and support during video tasks need more attention. Question (20) shows that the number of positive results (21) or neutral results (9) outweigh the negative results (6), indicating that with improvements, there is room for the implementation for further such tasks in an English communication class.

\subsection{Area 3 and Area 4}

The aim of our evaluation in area (3) was to see if students are comfortable with the project design to enable us to expand this phase of the study to include a wider learning context. In the initial trial (Table 1), the focus was on testing if students could use the technology. One of the key findings is that we were able to set up and collect data successfully in the form of video media, which was recorded outside the classroom and integrated vocabulary, language-learning and speaking formats on reader science topics (Table 2). This result is significant for two reasons. The first reason is that observations made by the teacher recognized that class time was made available for preparing language use and group discussions carried out in English. This provided the teacher with more time to assist students as well as to confirm the language and speaking goals. The second reason is that students were prompted to self-evaluate their videos before uploading them and to re-record videos for the purpose of improving their English, content, accuracy, intonation and fluency. In addition, students could also listen to group members' videos as many times as they wanted to, thereby giving students time to prepare question/answer videos and/or to share comment videos. By the completion of the first reader activity, the teacher in class observed that almost all concerns regarding the use of the technology had been overcome, thus allowing the teacher and the students to focus on the schoolwork. 
As a result, in the second reader exercise, observations showed that the focus withdrew from the technology, and instead, student attention was more self-directed towards the topic language. To successfully conduct a broader and primary study, it was concluded that the level of language and the teaching methodology and learning pedagogy should be carefully considered. Also, even though no training was instigated in the pilot phase to test the technology, a training session would have been beneficial to prevent some of the problems that were encountered, such as internet reliability. To conclude, these findings show that the use of Flipgrid as a method for students to complete speaking activities as part of formative assessment can promote successful outcomes in learning. As seen in the students' answers in the questionnaire, the students submitted overwhelmingly positive to neutral responses with only a few students submitting negative feedback. This indicates that the students felt comfortable with the lesson framework (Area 3 ) and how well lesson procedures were demonstrated and carried out and that language aims and objectives were successfully completed in class work and outside of class. Overall, these results give us a "proof of concept" so that we could justify the continuation of the study (Area 4). Now that future work for this study is viable, the next stage of the study is development work, and with attention paid to the noticeable areas for improvements, the design of the study can be established.

\subsection{Implications for Further Development}

During this study, there was an attempt to align a university ESL course with MEXT's calls for more communicative language teaching for English, while doing so by using a non-threatening Web 2.0 format. Based off of the student responses in the questionnaire, it would appear that by using Flipgrid, the students generally had no issues doing the assigned tasks and they felt that the assignments were useful. The overall high-scored responses are encouraging because it shows that the technology will not be a hurdle for the students to overcome, but rather something that an instructor can use to increase student English use inside and outside of the classroom. Furthermore, the combined activities done by the students in Flipgrid netted over 8,489 views with 102.6 hours of engagement, showing that this can, in fact, increase language interaction. Although such reports can generally be considered good news, there are still some issues that prospective instructors need to consider, such as the effectiveness of student-uploaded discussions, Wi-Fi connection, the recording environment and achievement(s) gained in activity objectives.

The first issue was the lack of providing instructions for effective student discussions. For the most part, videos tended to be a one-way conversation. Students would upload their video and their group members would reply with a simple short answer or follow-up question. It has become apparent that instructors need to scaffold and demonstrate what type of interaction is desired out of these assignments along with their goals and objectives; otherwise, students will not engage as deeply as expected.

Another problem that came up was the Wi-Fi connection and speed. When students tried to use their cellular data, they would run into situations where they could not download the applications or upload their videos. These troublesome problems were generally fixed by having the students connect to the campus Wi-Fi, even though the students noticed how much better it was when doing so, the instructors had to remind them every class otherwise there would inevitably be a couple of students who forgot and couldn't do what was required of them.

The video recording environment was another issue that came into play. Because of the desire to be able to assist students if technology problems arose, most of the videos were made in the classroom. This became an issue for the grading instructor as all the videos tended to have sound difficulties due to the fact that 37 students were recording their videos at the same time, thus creating a lot of background noise.

The final issue was the assigned tasks. It was felt that using the National Geographic readers was useful because they met the CEFR levels set for the course level, but giving presentations in Flipgrid using a smartphone did not meet nor have specific speaking expectations. In future work, doing more video discussions, much like a traditional text-based discussion forum, would lend itself more to the application's abilities and allow for the development of specific level speaking goals for assessment.

\section{Conclusion}

The volume of videos and engagement hours, along with the positive survey results, have shown that Flipgrid has provided ways for a teacher to set up activities with the aim of prompting students to communicate with each other inside and outside of the classroom. As previously mentioned, one of the factors for Flipgrid evaluation was to determine how well students were able to use smartphones in a traditional CALL environment. Not only were the Flipgrid assignments successfully completed by the students, but the pilot has proven that such a class is possible to be done only using student smartphones. Adding to the success of the pilot, it was noted that Fipgrid could easily be integrated into an existing Moodle LMS framework that is smartphone ready. Although this paper is not evaluating the exercises that were implemented in the course, the findings have shown that more work is 
needed in the implementation and instruction for better discussions to take place. The students were easily able to engage with each other using Flipgrid, showing that Japanese schools should not be hesitant about using such technologies in their classrooms. With that said, it is also recognized that a larger sample size or multiple trials would be beneficial in deciding how useful Flipgrid is for English communication classes. However, currently, Flipgrid in this trial has provided the right tool for the use of student smartphones in the delivery of subject-based speaking videos and also shows further potential for discussion through videos.

\section{References}

Allen, I. E. \& Seaman, C. A. (2007). Likert Scales and Data Analyses. Quality progress, 40(7), 64-65.

Allen, E. \& Seaman, J. (2013). Changing Course: Ten Years of Tracking Online Education in the United States. 1-42. Babson Survey Research Group and Quahog Research Group, LLC.

Borau, K., Ullrich, C., Feng, J. \& Shen, R. (2009, August). Microblogging for Language Learning: Using Twitter to Train Communicative and Cultural Competence. In International conference on web-based learning (pp. 78-87). Springer, Berlin, Heidelberg.

Butler, Y. G. \& Iino, M. (2005). Current Japanese Reforms in English Language Education: The 2003 “Action Plan." Language Policy, 4(1), 25-45. https://doi.org/10.1007/s10993-004-6563-5

Creswell, J. W. (2015). 30 essential skills for the qualitative researcher. Sage Publications.

Dimock, M. (2019, January 17). Defining generations: Where Millennials end and Generation Z begins. Retrieved January $12, \quad 2020, \quad$ from https://www.pewresearch.org/fact-tank/2019/01/17/where-millennials-end-and-generation-z-begins/

Dogoriti, E. (2015). Towards an instructional tool for the teaching of English as a second/foreign language $(E S L / E F L)$ in higher education. In international conference on information, communication technologies in education (Vol. 15, pp. 401-411).

Flanagan, B. \& Ph, D. (2019). Creating Community, Enhancing Engagement, and Fostering Verbal Expression Through A Video Discussion Platform. (April). https://doi.org/10.13140/RG.2.2.24667.62247

Given, L. M. (2016). 100 questions (and answers) about qualitative research. SAGE Publications.

International Telecommunications Union (2019). Measuring digital development Facts and figures. Retrieved December 17, 2019, from https://www.itu.int/en/ITUD/Statistics/Documents/facts/FactsFigures2019.pdf

McClure, C. \& McAndrews, L. (2016). Going Native to Reach the Digital Natives: New Technologies for the Classroom. 2016 ITAA Annual Conference Proceedings, 12, 8-10.n Retrieved from http://lib.dr.iastate.edu/itaa_proceedings/2016/presentations/135

McLain, T. R. (2018). Integration of the Video Response App Flipgrid in the Business Writing Classroom. International Journal of Educational Technology and Learning, 4(2), 68-75. https://doi.org/10.20448/2003.42.68.75

Mohamad Ali, A. \& Jabar, N. (2016). Cultural Video Project Assignment (VPA) through the Eyes of Young ESL Learners: A Multi-Modal Vocabulary Learning Approach. Indonesian Journal of EFL and Linguistics, 1(2). https://doi.org/10.21462/ijefll.v1i2.11

Mohd Hafiz Zakaria, M., Watson, J. \& Edwards, S. (2010). Investigating the Use of Web 2.0 Technology by Malaysian Students, Multicultural Education \& Technology Journal, 4(1), 17-29. https://doi.org/10.1108/17504971011034700

Motiwalla, L. F. (2007). Mobile Learning: A framework and Evaluation. Computers \& Education, 49(3), 581-596.

Okada, Y., Sawaumi, T. \& Ito, T. (2014). Different effects of sample performance observation between high-and low-level English learners. In The 6th Centre for Language Studies International Conference Proceedings (pp. 394-13). https://www.fas.nus.edu.sg/cls/CLaSIC/clasic2014/proceeding.htm

Okada, Y., Swaumi \& Ito, T. (2018). How Do Speech Model Proficiency and Viewing Order Affect Japanese EFL Learners' Speaking Performances? Review of Literature. Call-Ej, 19(2), 61-81.

Ozdamli, F. \& Cavus, N. (2011). Basic Elements and Characteristics of Mobile Learning. Procedia - Social and Behavioral Sciences, 28, 937-942 
Petersen, J, (2015). Honoring diversity in an online classroom: approaches used by instructors engaging through an LMS. Theses, Student Research, and Creative Activity: Department of Teaching. Learning and Teacher Education, 56. http://digitalcommons.unl.edu/teachlearnstudent/56

Shrosbree, M. (2008). Digital Video in the Language Classroom. The JALT CALL Journal, 4(1), 75 84. https://journal.jaltcall.org/issues/jaltcall-4-1

Spaniol, M., Li, Q., Klamma R. \& Lau R.W.H. (2009). (Eds.) Advances in Web Based Learning -

$I C W L$ 2009. ICWL 2009. Lecture Notes in Computer Science, vol 5686. Springer, Berlin, Heidelberg

Steele, D. \& Zhang, R. (2016). Enhancement of Teacher Training: Key to Improvement of English Education in Japan. Procedia - Social and Behavioral Sciences, 217, 16-25. https://doi.org/10.1016/j.sbspro.2016.02.007

Tapscott, D. (1998). Growing up digital (Vol. 302). McGraw-Hill Companies

Tossell, C. C., Kortum, P., Shepard, C., Rahmati, A. \& Zhong, L. (2014). You can Lead a Horse to Water but You Cannot Make Him Learn: Smartphone Use in Higher Education. British Journal of Educational Technology, 46(4), 713-724.

Townsend, S.D.C. \& Cronin, A. L. (2017). The Universal Access Framework: An Architecture for Uniting Learning with Mobile Phones. International Journal of Teaching, Education and Learning. Proceedings (29th International Conference on Teaching, Education \& Learning (ICTEL), 27-28 December 2017, Bangkok, Thailand).

Wilkinson, D. (2015). Educational Reforms and Development in Japan: Language and Culture Education for Global Competitiveness. International Journal of Higher Education Management, 1(2), 1-11.

\section{Copyrights}

Copyright for this article is retained by the author(s), with first publication rights granted to the journal.

This is an open-access article distributed under the terms and conditions of the Creative Commons Attribution license (http://creativecommons.org/licenses/by/4.0/). 